Drucker, Peter, F. The Changing world of the executive. New York, New York Times Book, 1982. XIV + 271 p.

Entre os artigos deste livro, 39 apareceram primeiro no Wall Street Jour. nal; outro, "The professor as featherbedder" (O professor se encosta), já fora publicado numa revista de educação superior; e "O negócio da ética em administração", na revista Public Interest. Portanto, é bem posslvel que a Gazeta Mercantil tenha publicado um ou outro destes artigos, pois, com acerto, coloca o Wall Street Journal, bem como Peter Drucker, na sua página editorial. Peter Drucker afirma que escolheu os artigos pelo seu interesse permanente - e mais uma vez ele acertou. Tudo que li neste livro fala de administração com A maiúsculo, e é para nós, no Brasil, tão atual quanto para um norte-americano leitor do Wall Street Journal, cuja circulação, hoje, ultrapassa 1,5 milhão de leitores primários - além dos secundários e terciários.

Do ponto de vista de resenhista é quase impossivel dar uma visão coordenada de tal aglomerado (não conglomerado, pois este trata de coisas diversas sob o mesmo teto) de opiniões e trouvées (achados) administrativos. Quando o autor é Drucker, o artigo em si já é bom. Estes foram escolhidos; assim, $\epsilon$ possível imaginar por que são ótimos. Aglomerado, pois há coletânea de diver. sos artigos sobre um mesmo títuloconjunto. São estes:

\section{A agenda do executivo}

2. O desempenho das empresas

3. O setor "sem fins lucrativos"

4. Gente trabalhando

5. O mundo em transição

6. Uma nota final - a ética em negócios ou o negócio da ética em administração.

Ler um livro de Peter Drucker me dá satisfação intelectual. Ele é um dos últimos sobreviventes das grandes escolas de administração e dos seus fundadores, homens que além dos títulos acadềmicos traziam consigo uma vasta bagagem de cultura (como, caso fossem ainda professores, José Mindlin, Celso Lafer, Gudin e, entre os professores, Simonsen, no Brasil). Ainda bem que Drucker fala dos professores que ficaram ensinando 20 anos e nunca pisaram numa fábrica ou qualquer outro ambiente estranho à sua torre de marfim.

Veja-se a profundidade e a aplicação ao Brasil de uma observação no capítulo "India e a tecnologia apropriada": "Com a quantidade de desemprego que temos, Gandhi fez um grande erro, disse um economista da India; devíamos ter, em lugar da roca, um simples rolo de fios." Mas Drucker ficou impressionado com o número de bicicletas em frente aos buracos onde vivem os desempregados e pobres - ora, não é também este o problema do Brasil?

Aliás, toda a parte econômica, do qual o capítulo citado faz parte lo mundo em transiçăo) é excelente, apesar de um tanto ultrapassados: os artigos sobre a crise japonesa de 1976 e 1977 tratam, na verdade, de assuntos que חão são mais atuais lexcesso de estoques e maneira de aumentar os preços internos para subsidiar a exportação e a reação norte-americanal; no entanto, continuam interessantes no contexto brasileiro atual.

O capítulo sobre a ética, o negócio da ética, é excelente, filosoficamente falando, ou praticamente, pois - autor parte do provérbio latino Quod licet Jovi non licet bovi lo que é bom para Júpiter não é permitido aos bois) - isto é, o que os poderosos e o governo fazem não é permiti. do aos bois - o que em termos claros nossos significa: o que a Receita Federal faz, retendo a restituição do imposto de renda, mesmo com correção monetária, não cabe ao pobre povo, que não pode deixar de pagar o imposto, com a promessa de pagar depois com correção. (Já se paga com correção, portanto leva multa). A ética falada também inclui o caso Lockhead e o Japão - o que Lockhead fez foi subornar uma empresa aérea japonesa, para poder manter o emprego de 25 mil operários, mas quando o negócio gorou, melhorou o lucro, a rentabilidade e a capacidade da Lockhead contra seus empregados. $E$ sofreu condenação moral (ética?).

A "Agenda do executivo", que é a primeira parte, é útil ; interessante e toca em problemas permanentes, como, por exemplo, a avaliação do executivo, quanto ele (ou cientista da empresa) deve ganhar e como o imposto de renda deveria levar em conta os salários etc, $\mathrm{O}$ segundo capítulo é exclusivamente dedicado à medida do desempenho da empresa, não do executivo. $O$ autor também estuda os mitos da economia americana, tais como: primeiro, a "obsolescência planejada" (:o automóvel norteamericano tem uma vida de trabalho mais longa, medida em milhas andadas, que qualquer outro carro"); segundo, que a atividade econômica dependa da procura pelo consumidor; terceiro, que o desemprego é necessario, mesmo com o fim de uma estagflação ou recessão; quarto, que há uma tendência por um excesso de economia. O quinto mito é o de que o imposto sobre lucros das empresas é um imposto que só atinge os ricos (pelos fundos de pensão, nos EUA atinge os operários), e finalmente o sexto mito, o de que poucos ganham muito e possuem muito, o mito da redistribuição da renda, que aparentemente também está na cabeca de ricos socialistas redistribuidores dos EUA, tal qual no Brasil.

Outro capítulo é aquele que trata do nível dos salários industriais norte-americanos, que fora da indústria automobilística e de aço é igual ao da Alemanha e do Japão. Portanto, a diferença toda está nesta duas indústrias.

O capítulo sobre o setor que não tem fins lucrativos, como escolas, hospitais, igrejas etc., começa a ter sua importância no Brasil. Nos EUA, um terço dos formandos em escolas de administração de empresas se dirige ao trabalho em setores sem fins lucrativos. Talvez o ponto mais importante do livro é o declínio da sindicalização nos EUA, e o capítulo dedicado ao professor, e como ele está mentalmente esgotado aos 40 anos, exceto quando trabalha na indústria. e a ela deve ser encaminhado. Não quero fazer nenhum paralelo com a política brasileira que enfatiza a dedicação integral, proíbe tanto quanto possivel, por vias econômicas, viagens ao exterior, penaliza o associado a associações científicas no exterior com 33\% do imposto de renda sobre a contribuição (em vez de permitir que seja subtraída do IR) e finalmente torna o livro proibitivo, principalmente quando importado. $E$ a vida 
universitária nacional é, portanto, estagnada.

O capítulo sobre "Gente trabaIhando" é definitivamente de máxima importância para quem estiver interessado (e quem não está?) na aposentadoria, por idade ou tempo de trabalho. Pois Drucker parte do princípio de que o nível de idade de aposentadoria do século passado foi ultrapassado, e hoje a pessoa está apta e deve trabalhar mais tempo. Em contrapartida, há os milhões que querem entrar no mercado de trabatho. Ao todo, considerações importantes, mesmo quando não se concorde com elas.

Ao terminar a leitura amena (po. de ser feita em partes, ou pode ser saboreada como um prato de frios), fica a impressão de uma tarde em presença de uma pessoa inteligente, com a qual se pode discutir até altas horas da noite. O livro é isso, um companheiro para uma conversa a dois, o autor e o leitor.

Kurt Ernst Weil

Professor titular no Departamento de Administração da Produção e Operações Industriais da EAESP/FGV e decano da Congregação.
Ianni, Octávio. Revolução e Cultura. Rio de Janeiro. Civilização Brasileira, 1983. $134 \mathrm{p}$.

Em certo sentido, Revolução e cultura vem a ser a retomada de uma série de temas já presentes em trabalho anterior de lanni, qual seja, imperialismo e cultura (1976). Autor de pelo menos uma dúzia de livros - entre os quais se destacam 0 Colapso do populismo no Brasil, Raças e classes sociais no Brasil, Estado e planejamento económico no Brasil, Ditadu. ra $e$ agricultura - neste Revolução e cultura, dedica-se à América Latina, onde as revoluções burguesas e socialistas levantam "problemas culturais de grande interesse, talvez ainda pouco conhecidos". E a análise desses problemas ajuda na explicação das revoluções, bem como levanta tópicos importantes para o estudo das ciências sociais, das artes, da filosofia, dos movimentos sociais e dos partidos políticos. Segundo o autor, "toda revolução abre novos problemas de cunho cultural, ao mesmo tempo que recoloca as implicações culturais das lutas sociais passadas. Além de abrir perspectivas novas, cada revolução-redescobre o passado e o presen. te $^{\prime \prime}$ (p. 9).

Uma das idéias centrais desta obra é a de que, nas ocasiōes revolucionárias, a cultura também acaba sendo colocada em xeque, simultaneamente com as condições sociais, econômicas e polfticas. A partir dessa perspecti va, vários aspectos da história cultu. ral dos palses latino-americanos podem ser examinados: "civilização, barbárie e exotismo; a revolução burguesa e a questão nacional; as relações da ciência, arte e filosofia com os movimentos da sociedade; o com. promisso e a distância entre o intelectual e as lutas sociais; as diferenças e as relações entre cultura 'erudita' e 'popular'; o romance da tirania; a transformação das idéias em forças sociais; a cultura do socialismo; a contribuição das revoluções de base operário-camponesa para a teoria da revolução socialista" (p. 9/10).

Ao longo dos sete capítulos de seu texto, Ianni se empenha no sentido de dar conta desses vários aspectos da história cultural arrolados no parágrafo anterior, sempre procuran. do evitar que a análise descambe para um tratamento culturalista. Isto é, não perde de vista as perspectivas econômica, política e social e a ma neira pela qual elas interagem com a cultural. Através da transcrição e comentário de longos trechos dos escritos de, por exemplo, Simón Bolívar, lanni elucida o quadro em que se insere a nossa dependência cultural. $\mathrm{Em}$ seu Discurso de Angostura (1819), Bolívar já falava que "não somos europeus, não somos índios, mas uma espécie de média entre nativos e espanhois (. . .). Tenhamos presente que o nosso povo não é europeu nem americano do norte; é mais uma mescla de Africa e Amé rica que uma expressão da Europa (. . .). E impossível dizer com propriedade a que família humana pertencemos (.. .). Atado ao triplo jugo da ignorância, tirania e vício, o povo americano não pode adquirir nem saber, nem poder, nem virtude".

Durante todo o período colonial, as sociedades formadas na América Latina se baseavam no trabalho compulsorio, principalmente sob a forma de escravatura. Negros e índios foram escravizados com a finalidade de produzir para as metropoles e para o consumo dos governantes e senhores nas colônias. Na condição de escravos ou semiescravos viviam os índios, mestiços, negros e mulatos, de senvolvendo-se a partir dar um largo processo de divisão social e racial do trabalho, conduzindo a uma estrutura social rígida (p. 14). No Brasil colônia, a estrutura social apresentou composição semelhante d̀ dos demais países vizinhos, sendo que essa estratificação social e racial persistiu mais ou menos semelhante ao longo do século $X \mid X$, ao final do qual se dá a abolição da escravatura. E essa abolição, logicamente, "não apagou de imediato a cultura produzida em cerca de três séculos de trabalho escra. vo e semiescravo. Também no século $\mathrm{XX}$ entraram os desdobramentos sociais, raciais e culturais do passado escravista, como herança de desigualdades que se recriam com as desigualdades e contradições de clas$\operatorname{ses}^{\prime \prime}$ (p. 15).

$\mathrm{Na}$ seqüência, Ianni explora outros aspectos que anunciara na apresentação de seu livro, quais sejam: a ação do imperialismo norteamericano sobre a região, detalhando um pouco mais a dominação cultural 